\title{
Design for Nonlinear Current Reference Deadbeat Control for Boost Converter
}

\author{
Aviti Mushi and Sakahisa Nagai \\ Graduate School of Engineering \\ Yokohama National University, Japan 240-8501 \\ Email: \{mushi-thadei-bf, nagai-sakahisa-yf\}@ynu.jp
}

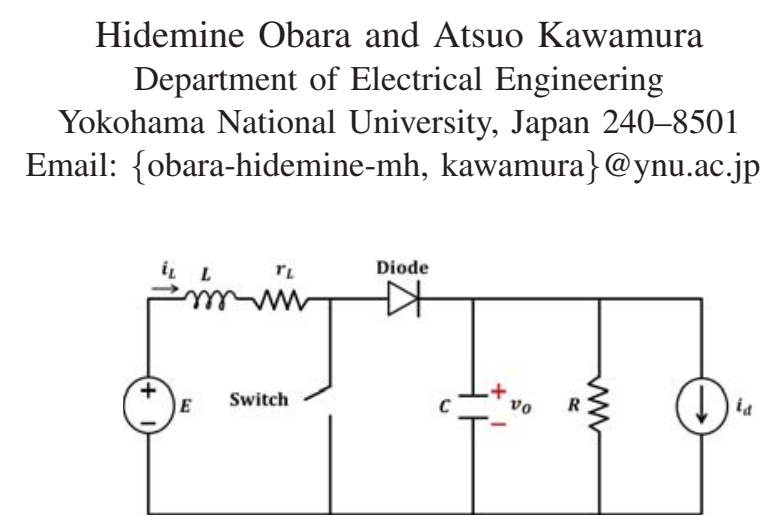

Fig. 1: Boost converter equivalent circuit.

\begin{abstract}
This paper describes a design for fast and robust nonlinear deadbeat control for boost DC-DC converters. Nonlinear current reference deadbeat control is derived based on nonlinear state equation of the converter. Load disturbance compensation is implemented thus forming a new robust nonlinear controller. Both experiments and simulations of boost converter with input $12 \mathbf{V}$, output $20 \mathrm{~V}$, load $4 \Omega$ and $100 \mathbf{~ k H z}$ sampling frequency, confirmed the voltage command tracking capability $266 \mu$ s settling time, and also disturbance rejection $1.20 \mathrm{~ms}$ recovery time. The method is applicable to boost converters of various applications.
\end{abstract}

\section{INTRODUCTION}

The performance of DC-DC converters may be evaluated by two kinds of performance index: (1) the command voltage tracking capability and (2) robustness to the disturbances.[1], [2] Among several DC-DC converters, the boost type has an unstable zero in the plant, thus it has difficulties in higher performance. Literature survey on boost type converters is reported as follows. Karamanakos et al. [3] presented direct voltage control based on enumeration model predictive control for boost converter input $15 \mathrm{~V}$, output $30 \mathrm{~V}$, load $15 \Omega$. Results indicated settling time $1900 \mu$ s and recovery time $0.7 \mathrm{~ms}$. Shirazi et al [1] proposed an online tuning control based on the system-identification algorithm called pseudo random binary sequence perturbation. Plant parameters are identified online then digital PID controller regulates the output voltage. With input $15 \mathrm{~V}$, output $30 \mathrm{~V}$ load $100 \Omega$, and sampling frequency $195 \mathrm{kHz}$, the voltage command tracking capability $800 \mu \mathrm{s}$ settling time and the output voltage recovery time $0.6 \mathrm{~ms}$ were reported. Tong et al [4] reported sensorless predictive peak current control using minor current deadbeat controller based on the state space average model together with digital PID control regulated output voltage. With $5 \mathrm{~V}$ input, output regulated at $15 \mathrm{~V}, 10 \Omega$ load and $100 \mathrm{kHz}$ sampling frequency, the input voltage was abruptly changed from $5 \mathrm{~V}$ to $6 \mathrm{~V}$ and the output voltage dip recovered within $0.18 \mathrm{~ms}$. However the output voltage tracking command capability was not mentioned and the related references [5], [6], [7], [8] indicated a few ms settling time for the voltage command tracking.

Authors propose a new discrete time domain nonlinear state equation and nonlinear deadbeat control for a boost converter with a current minor loop. [9] The load current observer is implemented aiming the disturbance robustness based on this modeling. As a result under the conditions of input voltage $12 \mathrm{~V}$, output voltage $20 \mathrm{~V}$, the load resistor 4 $\Omega$ and $100 \mathrm{kHz}$ sampling frequency, the voltage command tracking capability $266 \mu$ s settling time was confirmed, and also $1.20 \mathrm{~ms}$ output voltage recovery time was experimentally achieved for a sudden load change. These data seem among the best even though the proposed control is based on nonlinear equations.

Section II of this paper describe control scheme of nonlinear deadbeat control and consequent several kinds of control law are proposed, and the Section III presents simulations and experiments. Features of this proposed control are discussed in the Section IV, and the Section V concludes the paper.

\section{THEORY OF NONLINEAR DEADbEAT CONTROL FOR BOOST CONVERTER}

This section presents the theoretical framework of the nonlinear deadbeat control. The nonlinear state equation derived in [10] is used to propose a nonlinear current reference deadbeat control. [9] The load disturbance compensation is implemented, and as a final result, a new nonlinear controller is proposed in Fig. 4.

\section{A. Basic Definitions for Deadbeat Control}

Figure 1 shows the equivalent circuit of a boost converter. Input voltage is $E$, inductance is $L$, current through inductor is $i_{L}(t)$, and inductor ESR is $r_{L}$. The output capacitor is $C$, output load resistor is $R$ and output voltage is $v_{O}(t)$. The load disturbance is represented by the current source $i_{d}(t)$ attached at the output. The $t$ symbolizes continuous time index. Deadbeat control is derived based on the waveforms presented in Fig. 2. The $\Delta T_{1}[k]$ and $\Delta T_{2}[k]$ are $\mathrm{ON}$ and OFF switching duration of the switch respectively. The sampling period is given as $T_{s}=\Delta T_{1}[k]+\Delta T_{2}[k]$. The pulse width duration $\Delta T_{2}[k]$ is placed at the center of the sampling period. The $k$ symbolizes the discrete time index. 


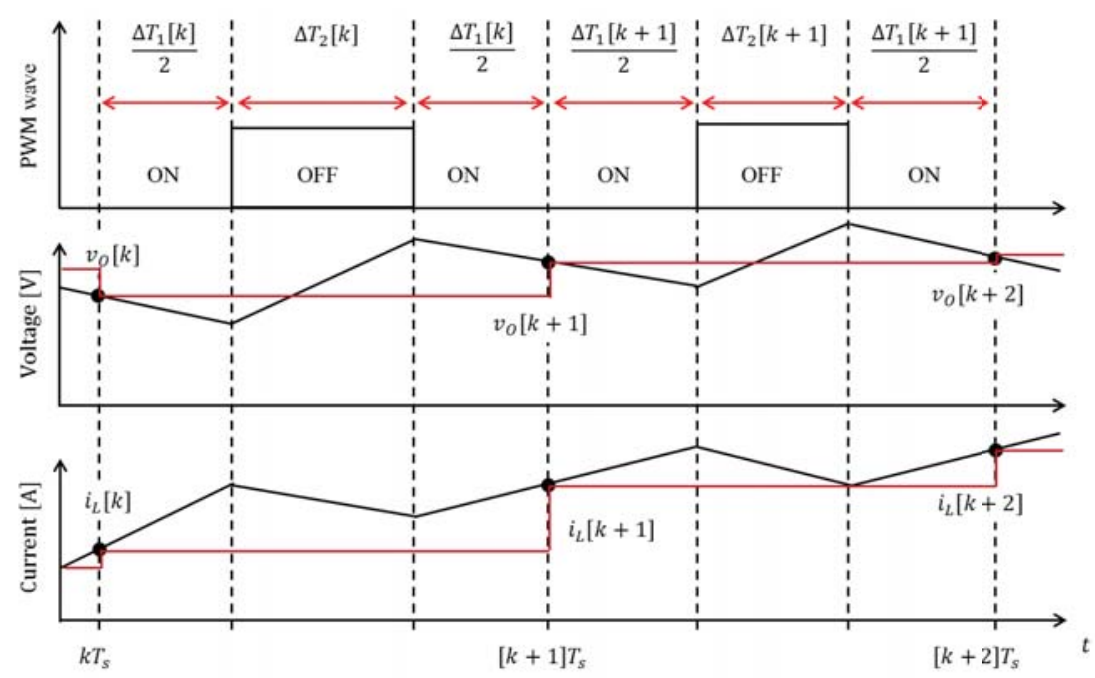

Fig. 2: Deadbeat control waveforms: black - actual waveform, red - sampled waveform.

\section{B. Derivation of Sampled Data Nonlinear Model}

With reference to boost topology of Fig. 1, waveforms in Fig. 2, and utilizing Euler's forward approximation method the nonlinear sampled data model [10], [11] of boost converter is derived. From which voltage and current sampled data nonlinear equations are given by (1) and (2) [10].

$$
\begin{aligned}
& v_{O}[k+1]=\left(1-\frac{T_{s}}{R C}\right) v_{O}[k]+\frac{1}{C} i_{L}[k] \Delta T_{2}[k]-\frac{T_{s}}{C} i_{d}[k] \\
& i_{L}[k+1]=\left(1-\frac{r_{L}}{L} T_{s}\right) i_{L}[k]-\frac{1}{L} v_{O}[k] \Delta T_{2}[k]+\frac{T_{s}}{L} E
\end{aligned}
$$

The equations are nonlinear especially $i_{L}[k] \Delta T_{2}[k]$ in (1) and $v_{O}[k] \Delta T_{2}[k]$ in (2) show very strong bilinear characteristics. Which are utilized for digital control 'the nonlinear deadbeat control' proposed in the next Section.

\section{Nonlinear Current Reference Deadbeat Control [9]}

Nonlinear deadbeat controller developed based on (1) suffers from the duty ratio saturation for high gain parameters and oscillatory output voltage resulting into very slow response. [10] Nonminimum phase nature of boost converter causes inverse response when a sudden change of duty ratio occurs, further influencing this slow response. The saturation of the duty ratio is mainly due to the large current in the switching device. Thus the inductance current is directly controlled by a new approach "current reference deadbeat control." [9] In this paper this concept is modified for boost converter. Using (2) and changing the $i_{L}[k+1]$ to $I_{\text {ref }}[k+1]$, the new control law "current reference nonlinear deadbeat" law is proposed (3).

$$
\Delta T_{2}[k]=\frac{\left(1-\frac{r_{L}}{L} T_{s}\right) i_{L}[k]-I_{r e f}[k+1]+\frac{E}{L} T_{s}}{\frac{1}{L} v_{O}[k]}
$$

The feature of this control is how to determine one sampling ahead current reference $I_{r e f}[k+1]$, the selection of which is very important because this value enables the very quick response under the current limit of the switching device. The current reference [9] is decided by (4).

$$
I_{\text {ref }}[k+1]=A\left(v_{\text {ref }}[k+1]-v_{O}[k]\right)+I_{\text {Lave }}[k]
$$

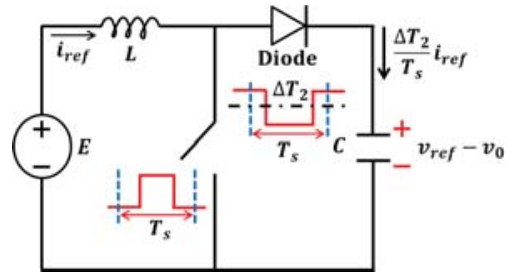

Fig. 3: Capacitor and inductor energy exchange.

The first term is based on the output voltage error and this regulates the output voltage. The second term is a steady state inductance current. These two terms will be discussed in the next sections.

1) Selection of $A$ in (4): The gain $A$ is selected as follows. [9] Figure 3 is a simple boost converter switching model. The injected energy into the inductor when the switch is on, and the energy in the capacitor due to the voltage change are assumed to be the same, thus (5) is derived.

$$
\frac{1}{2} L i_{r e f}^{2}[k+1] \frac{\Delta T_{2}[k]}{T_{s}}=\frac{1}{2} C\left(v_{r e f}[k+1]-v_{O}[k]\right)^{2}
$$

Solving this for $i_{\text {ref }}[k+1]$ yields,

$$
i_{\text {ref }}[k+1]=\sqrt{\frac{C}{L} \frac{T_{s}}{\Delta T_{2}[k]}}\left(v_{r e f}[k+1]-v_{O}[k]\right) .
$$

Comparing (4) and (6), $A$ may be given by (7).

$$
A \equiv \sqrt{\left(\frac{C}{L}\right)\left(\frac{T_{s}}{\Delta T_{2}[k]}\right)}
$$

The actual selection of $A$ is done based on (7) by trial and error during the experiments and simulations.

2) Selection of $I_{\text {Lave }}(s)$ in (4): The state space averaging method is used to calculate the $I_{\text {Lave }}(s)$. The derived model is shown in Fig. 4, where other parts will be explained later. Assuming the disturbance $i_{d}(s)=0$, then the averaging output 
current $i_{A}(s)$ is obtained as an inverse system of the plant, low pass filtered (LPF) as follows:

$$
\hat{i}_{A}(s)=\left(\frac{w_{O}}{s+w_{O}}\right)\left(\frac{s R C+1}{R}\right) v_{O}(s) .
$$

Boost converter operation provides that inductance average current $I_{\text {Lave }}(s)$ be proportional to $T_{s} / \Delta T_{2}(s)$ and $\hat{i}_{A}(s)$, but $\Delta T_{2}(s)$ has high frequency components, thus it should be LPF,

$$
I_{\text {Lave }}(s)=\left(\frac{w_{C}}{s+w_{C}}\right)\left(\frac{T_{s}}{\Delta T_{2}(s)}\right) \hat{i}_{A}(s) .
$$

This is a kind of nonlinear filter shown in Fig. 4, and it is one of unique features of this control law. The selection of $w_{O}$ and $w_{C}$ is as follows. $w_{O}$ is the cut-off frequency of the load current smoothing effect, thus it should be a little lower than the LC filter. $w_{C}$ is the cut-off frequency of the duty cycle averaging, thus it should be selected based on the switching frequency and the disturbance rejection as discussed later.

3) Suppression of Disturbance: When a sudden change of load happens, the output voltage drops for a while and the output voltage recovers to the reference voltage depending on the voltage regulator control. This period is defined as a recovery time and for shortening this time, a new disturbance observer (DOB) is proposed. In Section II-C2 the average load current was estimated, however, a disturbance current has higher frequency components and can be estimated by a DOB and feed forward the estimated current to the second term in (4). The plant model is again based on the state space averaging model, thus the block in Fig. 4 is applicable. The estimated disturbance $\hat{i}_{d}(s)$ is calculated by

$$
\hat{i}_{d}(s)=\frac{w_{o b s}}{s+w_{o b s}}\left(\frac{\Delta T_{2}(s)}{T_{s}} i_{L}(s)-\frac{s R C+1}{R} v_{O}(s)\right) .
$$

This signal is added to the $\hat{i}_{A}(s)$ in (9) to become

$$
\hat{i}_{A}(s)=\left(\frac{w_{O}}{s+w_{O}}\right)\left(\frac{s R C+1}{R}\right) v_{O}(s)+\hat{i}_{d}(s) .
$$

This new $\hat{i}_{A}(s)$ should be LPF by (9). The derived disturbance suppression is shown in Fig. 4 and implemented digitally by Tustin transformation.

4) Overall Control Block Diagram and Free Parameters: The derived overall control law is summarized in Fig. 4, in which digital control and analogue control are drawn together for simplicity. However, analogue control (8) - (11) is actually realized digitally by Tustin transformation. The left hand upper block is the nonlinear deadbeat part, and the left hand lower block is responded to the DOB, and the right hand block is the plant. There are several free parameters in Fig. 4, which are (1) load current observer cut-off frequency $w_{O}$, (2) boost converter switching frequency smoothing filter frequency $w_{C}$, and (3) DOB cut-off frequency $w_{\text {obs }}$. $i_{\text {ref }}$ gain $A$ is also a little changeable.

\section{SiMULATIONS AND EXPERIMENTS}

This section presents the simulations and experiments conducted to verify the proposed nonlinear current reference deadbeat control law for boost converter.
TABLE I: Boost Converter Parameters.

\begin{tabular}{cccc}
\hline \hline Parameter & Symbol & Value & Units \\
\hline Inductance & $L$ & 22 & $\mu \mathrm{H}$ \\
Inductor ESR & $r_{L}$ & 0.05 & $\Omega$ \\
Capacitance & $C$ & 60 & $\mu \mathrm{F}$ \\
Resistor load & $R$ & 4 & $\Omega$ \\
Input DC voltage & $E$ & 12 & $\mathrm{~V}$ \\
Switching frequency & $f_{s}$ & 100 & $\mathrm{kHz}$ \\
Sampling period & $T_{s}$ & 10 & $\mu \mathrm{s}$ \\
\hline
\end{tabular}

Simulations were done using the power electronics simulations software (PSIM). Conditions and circuit components values are summarized in Table I.

Experiments on the boost converter with parameters from Table I used a digital control system with a floating point digital signal processor (DSP) TMS320F28335.

\section{A. Voltage Reference Tracking}

The voltage reference was abruptly changed from 14.64 $\mathrm{V}$ to $20.0 \mathrm{~V}$. Performance index measured is voltage settling time $\left(t_{s}\right)$ which is defined as the period for the voltage to rise from $0 \%$ and stay within $90 \%$ of the voltage command. Simulated voltage tracking in Fig. 5a show $t_{s}$ shortening as gain $A$ increases; and experiment confirmation in Fig. 5b show $t_{s}=266 \mu \mathrm{s}$. The inductor current is controlled to the reference, during the voltage tracking in Fig. 6a for simulation and Fig. $6 \mathrm{~b}$ for experiments with good agreements.

\section{B. Disturbance Suppression}

Load disturbance was input by a sudden connection of unknown resistor bank to the output of the converter. Performance index measured is the voltage recovery time $\left(t_{r e c}\right)$ defined as the period for the voltage to recover from $100 \%$ voltage dip to when about $90 \%$ of the voltage dip is recovered for sudden disturbances. Simulated voltage recovery in Fig. 7a shows little change as $A$ increases; and experiment confirmation in Fig. 7b show $t_{\text {rec }}=1.20 \mathrm{~ms}$.

\section{Discussions}

This section presents observations made from the experiment results and discusses the stability.

\section{A. Originality of this Research}

This paper has achieved the following contributions. It has used sampled data modeling to develop a nonlinear current reference deadbeat control for a boost converter. The current reference is made of two terms, one is the output voltage regulation and the other is the estimated steady state inductance current. Then load DOB is proposed and is added to this current reference term for feedforward compensation. Finally a very quick reference voltage tracking was experimentally achieved among other literature while the disturbance recovery time is in the reasonably quick range. 


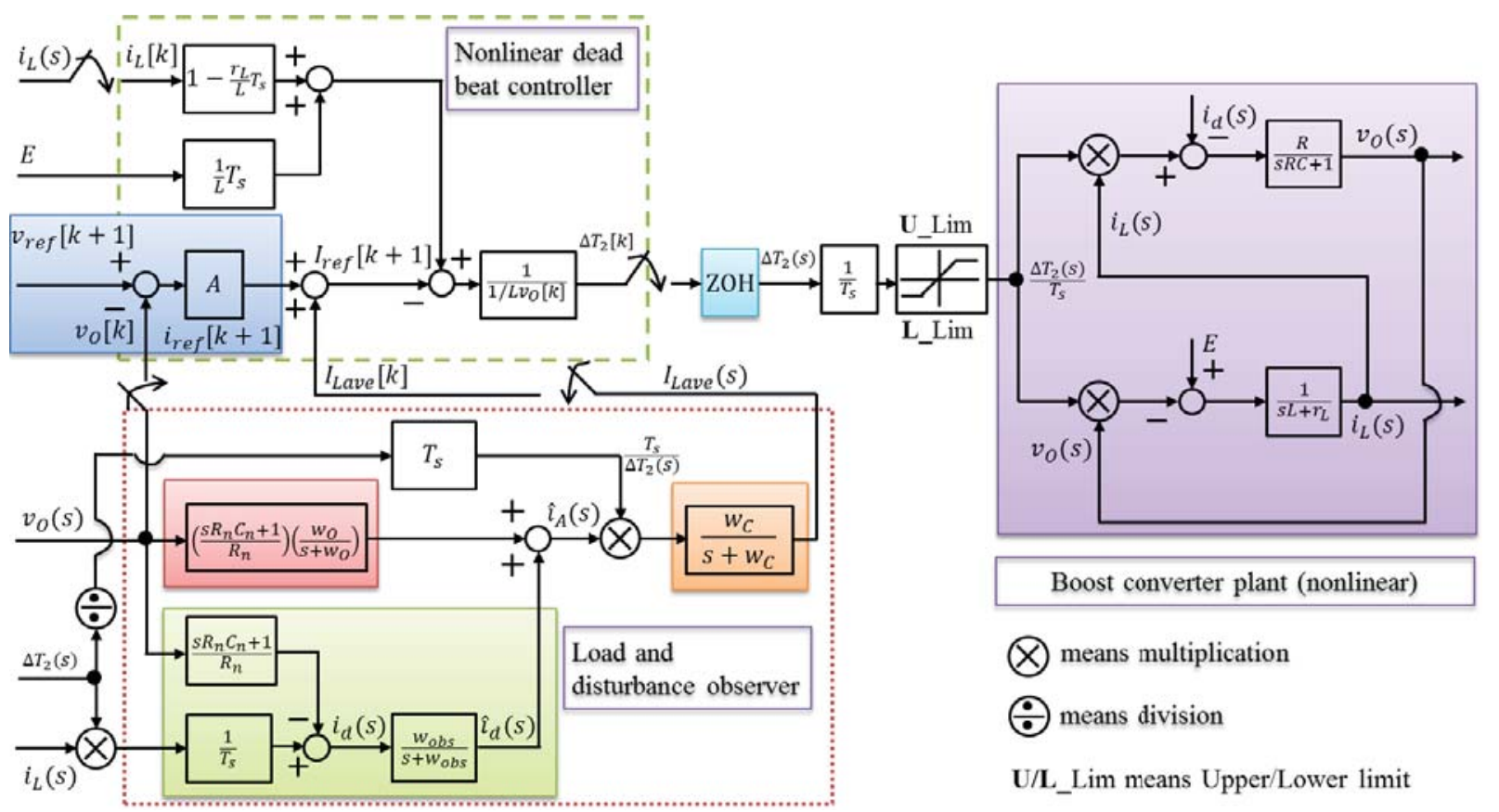

Fig. 4: Proposed nonlinear deadbeat control block diagram including disturbance observer.

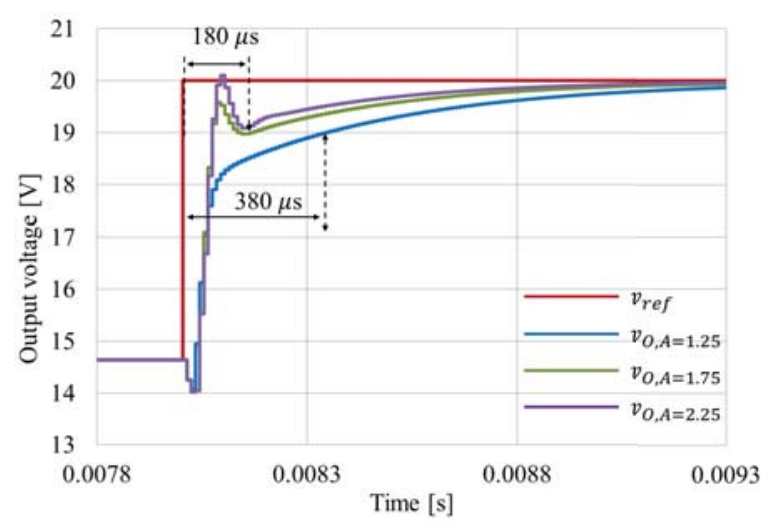

(a) Simulation results for of $A=\{1.25,1.75,2.25\}$.

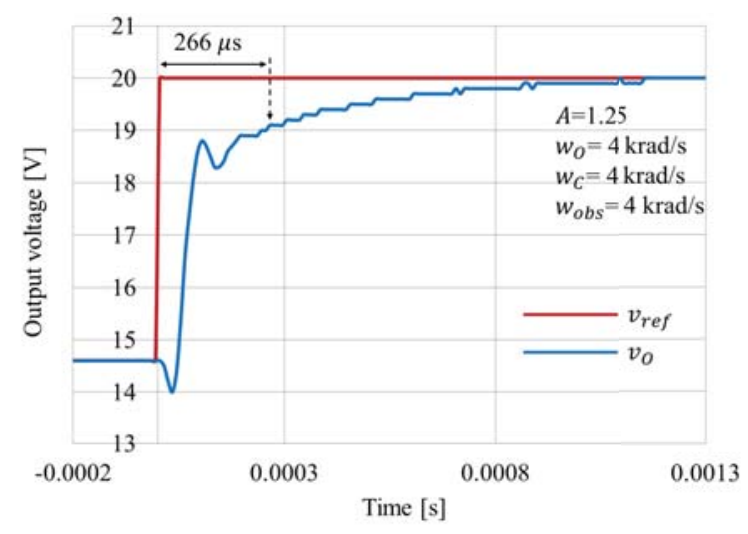

(b) Experiment results for $A=1.25$.

Fig. 5: Output voltage and reference, $\left(w_{O}=w_{C}=w_{o b s}=4 \mathrm{krad} / \mathrm{s}\right)$.

The selection of the three parameters in Fig. 4 is done as follows. The $w_{O}$ is the smoothing filter for the average load, and it should be the lowest among $w_{C}$ and $w_{o b s}$. $w_{C}$ is the cut-off frequency of the low pass filter for the nonlinear term $T_{s} / \Delta T_{2}(s)$. It should be a little higher than $w_{O}$. Also $w_{o b s}$ is the cut-off frequency of the load DOB, thus it should be high enough to compensate the high frequency disturbance components. As a result following conditions may be reasonable.

$$
w_{O}<w_{C}, w_{O}<w_{o b s}, w_{C} \leq w_{o b s}
$$

This suggestion is confirmed in Figs. $8 \mathrm{a}$ and $8 \mathrm{~b}$ results from experiments. Authors could use (7) to calculate $A$ in simulations, but they found that the square root and inverse operation involved in (7); while possible in PC, when implemented in
DSP caused unstable behavior. Thus they chose constant gains ( $A=1.25$ for experiments, to avoid overshoot) and $(A=1.25$, 1.75 , and 2.25 for simulations). Then setting $w_{O}=4 \mathrm{krad} / \mathrm{s}$, authors carried out investigations on effects of different DOB filters $\left(1.0 \leq w_{\text {obs }} \leq 5.0 \mathrm{krad} / \mathrm{s}\right)$ and different inductor current estimation filters $\left(1.0 \leq w_{C} \leq 5.0 \mathrm{krad} / \mathrm{s}\right)$ on $t_{s}$ and $t_{r e c}$. Results of these experiments are shown in Figs. 8a and 8b. Due to condition in (12) and arrangements of Fig. 4, $w_{C}$ could shorten the settling time than does $w_{o b s}$ see Fig. 8a. Figure $8 \mathrm{~b}$ shows the disturbance rejection capability increases with increase of both $w_{o b s}$ and $w_{C}$. For example choosing $w_{\text {obs }}=w_{C}=5.0 \mathrm{krad} / \mathrm{s}$ cause $t_{r e c}=1.05 \mathrm{~ms}$, which is reasonably fast, however it would cause a large overshoot and oscillations. Thus a lower setting is reasonable. 


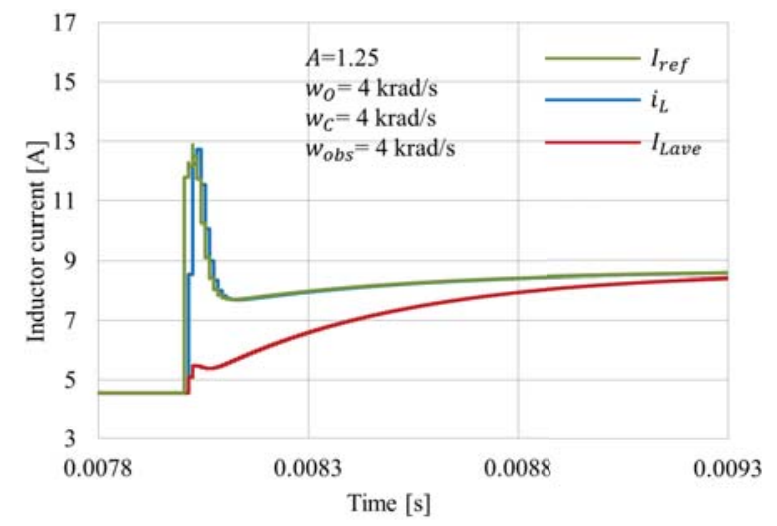

(a) Simulation

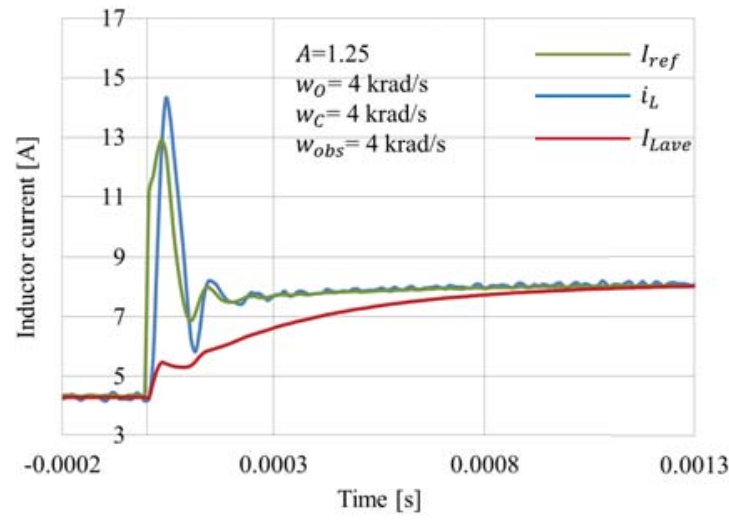

(b) Experiment

Fig. 6: Inductor currents during voltage tracking (simulations and experiments) for $A=1.25$.

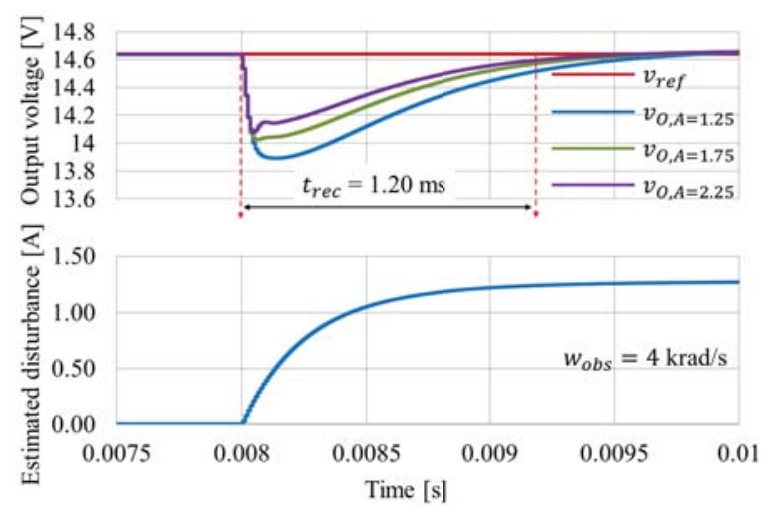

(a) Simulation recovery time $1.20 \mathrm{~ms}$

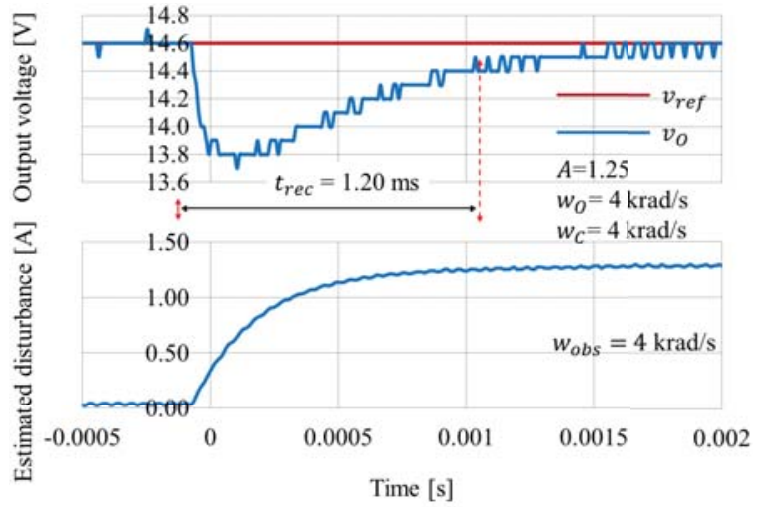

(b) Experiment recovery time $1.20 \mathrm{~ms}$

Fig. 7: Upper curves: the output voltage with the reference, bottom curves: the estimated disturbance.

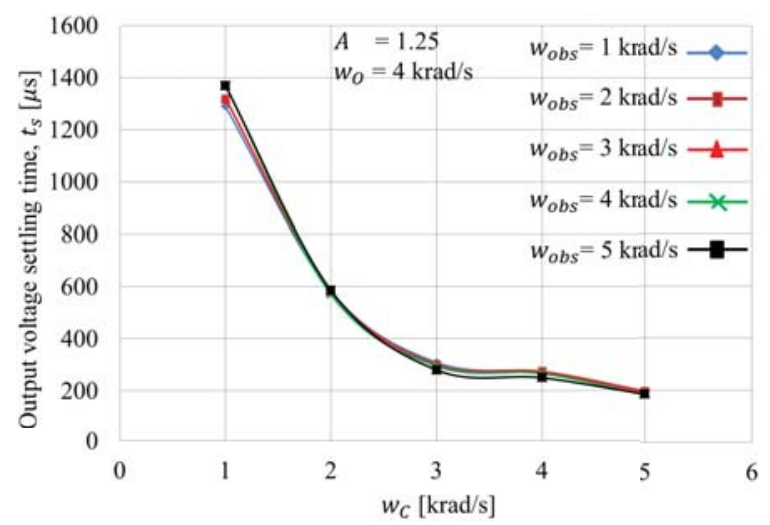

(a) Settling time

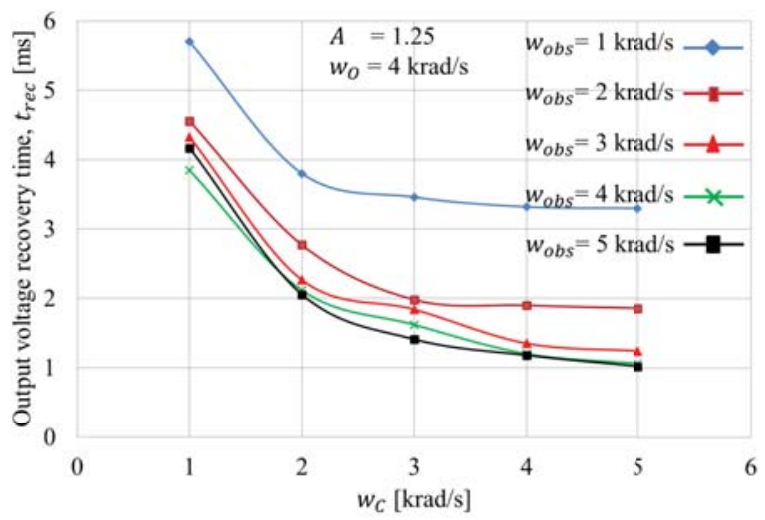

(b) Recovery time

Fig. 8: Experiment results of settling time $\left(t_{s}\right)$ and recovery time $\left(t_{r e c}\right)$. 


\section{B. Simplified Stability Explanation}

The detailed stability analysis is beyond the scope of this paper. However a simplified version follows. Putting (3) and (4) into (2) yields (13).

$$
i_{L}[k+1]=I_{\text {ref }}[k+1] .
$$

Assuming $i_{d}[k]=0$, then substitute (3), (4) and (13) into (1) to give (14).

$$
v_{O}[k+1]=\left(1-\frac{T_{s}}{R C}\right) v_{O}[k]+\frac{T_{s}}{C} i_{L}[k]\left(\frac{E-r_{L} i_{L}[k]}{v_{O}[k]}\right)_{(14)}
$$

At the steady state point, (4) and (13) imply that $I_{r e f}[k]_{k=\infty}=$ $I_{\text {Lave } \infty}$ and steady state output voltage is $v_{O}[k]_{k=\infty}=V_{\infty}$. Putting these into (14) gives

$$
\frac{1}{R} V_{\infty}=I_{\text {Lave } \infty}\left(\frac{E-r_{L} I_{\text {Lave } \infty}}{V_{\infty}}\right) .
$$

Small perturbation occurring around the equilibrium point is presented in following.

$$
v_{O}[k]=V_{\infty}+\Delta v_{O}[k], v_{O}[k+1]=V_{\infty}+\Delta v_{O}[k+1]
$$

Putting (16) into (14) and using (15) under the assumption that current $i_{L}[k]$ is constant $\left(I_{\text {Lave } \infty}\right)$, and approximating $1 / v_{O}[k] \approx\left(1 / V_{\infty}\right)\left(1-\Delta v_{O}[k] / V_{\infty}\right)$ gives (17) solved as (18).

$$
\begin{gathered}
\Delta v_{O}[k+1]=\left(1-\frac{2 T_{s}}{R C}\right) \Delta v_{O}[k] . \\
\Delta v_{O}[k]=\left(1-\frac{2 T_{s}}{R C}\right)^{k} \Delta v_{O}[0] .
\end{gathered}
$$

The eigenvalue $\left(1-2 T_{s} /(R C)\right)^{k}$ gets smaller as $k \rightarrow \infty$, thus $\Delta v_{O}[k]$ will asymptotically converge to zero.

\section{Transient Oscillations Observed in Figs. $5 a$ and $5 b$}

When (17) is derived, authors assumed constant current $i_{L}[k]$, however the transient phenomena in Figs. $5 \mathrm{a}$ and $5 \mathrm{~b}$ suggests that $i_{L}[k]$ is not constant. This is observed in Figs. 6a and $6 \mathrm{~b}$. Thus with current variation $\Delta i_{L}[k]$

$$
i_{L}[k]=I_{\text {Lave } \infty}+\Delta i_{L}[k],
$$

using (15), (16), and (19) substituted into (14) yields

$$
\begin{aligned}
\Delta v_{O}[k+1] & =\left(1-\frac{T_{s}}{R C}(2+\alpha[k])\right) \Delta v_{O}[k]+\frac{T_{s}}{R C} V_{\infty} \alpha[k] \\
& -\frac{T_{s}}{R C} \frac{r_{L} I_{\text {Lave } \infty}(1+\alpha[k]) \alpha[k]}{E-r_{L} I_{\text {Lave } \infty}}\left(V_{\infty}-\Delta v_{O}[k]\right),
\end{aligned}
$$

where current error ratio is $\alpha[k] \equiv \Delta i_{L}[k] / I_{\text {Lave } \infty}$. Therefore large $\alpha[k]$ causes (20) overshoot in the transient. The nonlinear product $\left(\Delta v_{O}[k] / V_{\infty}\right) \alpha^{2}[k]$ causes oscillations of (20). When $\left(r_{L} I_{\text {Lave } \infty}\right) / E \approx 0$, then (20) simplifies to

$\Delta v_{O}[k+1]=\left(1-\frac{T_{s}}{R C}(2+\alpha[k])\right) \Delta v_{O}[k]+\frac{T_{s}}{R C} V_{\infty} \alpha[k]$.

Which means that both $\Delta v_{O}[k]$ and $\alpha[k]$ decay to zero within few sampling instants due to applied deadbeat control.
Simulation and experiment showed that a very large gain $A$ in (4) made the feedback system unstable. The precise investigation of this nonlinear phenomena and others is very complicated therefore will be reported in future publication.

\section{CONCLUSiON}

This paper proposes a fast and robust nonlinear reference current deadbeat control for boost DC-DC converters. The nonlinear state equation is used to propose a nonlinear current reference deadbeat control. The current reference is made of two terms, one of which is for the output voltage regulation and the other is for the estimated steady state inductance current. Implementing the load disturbance compensation a new nonlinear controller was proposed. Verification by simulations and experiments confirmed the utility of this method. Under input voltage $12 \mathrm{~V}$, output voltage $20 \mathrm{~V}$, the load resistor $4 \Omega$ and $100 \mathrm{kHz}$ sampling frequency, the voltage command tracking capability $266 \mu \mathrm{s}$ settling time was achieved, and also 1.20 ms output voltage recovery time was realized for a sudden unknown load change. These data seems the best value among other literature. Simplified stability analysis show error decays asymptotically, thus system is stable.

This method can be implemented to boost converter of any continuous conduction mode application. Detailed stability analysis, precise investigation of nonlinear phenomena will be reported in future publication.

\section{REFERENCES}

[1] M. Shirazi, R. Zane, and D. Maskimovic, "An autotuning digital controller for DC-DC power converters based on online frequencyresponse measurement," IEEE Trans. Pow. Electron., vol. 24, no. 11, pp. 2578-2588, 2009.

[2] M. K. Kazimierczuk, Pulse-width modulated DC-DC power converters. Wiley, 2008.

[3] P. Karamanakos, T. Geyer, and S. Manias, "Direct voltage control of DC-DC boost converters using enumeration-based model predictive control," IEEE Trans. Power Electron., vol. 29, no. 2, pp. 968-978, 2014.

[4] Q. Tong, Q. Zhang, R. Min, X. Zou, Z. Liu, , and Z. Chen, "Sensorless predictive peak current control for boost converter using comprehensive compensation strategy," IEEE Trans. Ind. Electron., vol. 61, no. 6, pp. 2754-2766, 2014.

[5] J. Chen, A. Prodic, W. Erickson, and D. Maksimovic, "Predictive digital current programmed control," IEEE Trans. Power Electron., vol. 18, no. 1, pp. 411-419, 2003.

[6] S. Bibian and H. Jin, "High performance predictive dead-beat digital controller for DC power supplies," IEEE Trans. Power Electron., vol. 17, no. 3, pp. 420-427, 2002.

[7] Y. S. Lai and C. A. Yeh, "Predictive digital-controlled converter with peak current-mode control and leading-edge modulation," IEEE Trans. Ind. Electron., vol. 56, no. 6, pp. 1854-1863, 2009.

[8] A. Mushi, T. Nozaki, and A. Kawamura, "Proposal for faster disturbance rejection of boost DC-DC converter based on simplified current minor loop," in Proc. of IEEE 2nd Intern. Future Energy Electron. Conf. IEEE, 2015, pp. 1-6.

[9] S. Mizushima, A. Kawamura, I. Yuzurihara, A. Takayanagi, and R. Ohma, "Development of DC-DC converter for High/Low pulse voltage output using deadbeat control," in Proc. of IEEE 2nd Intern. Future Energy Electron. Conf. IEEE, 2015, pp. 1-6.

[10] A. Mushi, S. Nagai, and A. Kawamura, "Nonlinear deadbeat control for boost converter," in Proc. of IEEJ Intern. Workshop on Sensing, Actuation, Motion Control, and Optimization. IEEJ, 2016, pp. 1-2.

[11] A. Kawamura, R. Chuarayapratip, and T. Haneyoshi, "Deadbeat controlled PWM inverter with modified pulse patterns," IEEE Trans. Ind. Electron., vol. IE-35, no. 2, pp. 295-300, 1988. 